\title{
DESCRIPTIVE ANALYSIS OF PERCEIVED CHANGE ACCEPTANCE AND CHANGE REJECTION IN BANKS IN NORTH CENTRAL NIGERIA
}

\author{
Danlami Joseph Aduku \\ Department of Business Administration, Kogi State University, Anyigba, Nigeria \\ danlamijosephaduku01@gmail.com \\ Olanrewaju Makinde Hassan \\ Department of Business Administration, Kogi State University, Anyigba, Nigeria \\ olanrewajuhassan75@yahoo.com
}

Akeem Tunde Nafiu

Centre for Pre-degree and Diploma Studies, Kogi State University, Anyigba, Nigeria

tundenafiu01@gmail.com

\begin{abstract}
This study aimed at analysing perceived change acceptance and change rejection in banks in North Central Nigeria. The study used review strategy and survey strategy. Staff of Systematic Important Banks (SIBs) was the object of interest. For the sample size, given the population for each state (Benue- 168 and Kogi- 202) in the North Central, Sallant and Dillman's method was used to arrive at 189. Data were analysed using descriptive analytical techniques. Finding showed that employees' change rejection factors such as perceived change outcomes and change methods are the strongest factors in Benue State while bank employees are likely to reject organizational change on the basis of change type or methods in Kogi State. Finding further showed that the attitude of employees towards change is the strongest factors influencing acceptance of organizational change in Benue State, and that change based on complexity is the strongest factors influencing acceptance of organizational change in banks in Kogi State. The study concluded that employees' change resistance or rejection is subject to numerous factors. The study recommended that bank leaders should monitor change outcomes and change methods in Benue State, and that change type or methods should be given strong attention in Kogi State.
\end{abstract}

Keywords: Perceived Change Acceptance, Systematic Important Banks, Change Rejection, Perceived Change Outcomes, Change Methods

DOI: https://doi.org/10.24818/beman/2021.11.2-04 


\section{INTRODUCTION}

Banks' ability to accept change has established illumination in their operations and competitiveness in the banking industry. Westenholz (2013) insisted that change is paramount regardless of its concomitant challenges which Nigerian firms must combat. Although, the systemic approach instituted by the Central Bank of Nigeria seems to have muscled many banks' adaptive capability, but the global challenges and demands which dictate that the dynamism of change cannot be eroded in the banking sector. Most worrisome of the challenges in the recent time are ability to cope with e-payment, ebusiness and e-fraud.

In most cases, organizational change is the antecedent of the dynamism of the banking environment of Nigeria. Planned change is engineered by banks today as a proactive or strategic approach towards the dynamic nature of the banking environment today. In this context according to Liebhart and Lorenzo (2010), decision-makers strive to find some stability in the presence of uncertainty using planned methods of change while being aware of the need for flexibility and agility to leverage emerging change and survive it. Cummings \& Worley (2009) argued that organizational change is a reflection of the unknown. This implies that changes that organizations witness are products of the unknown, relative to the dynamic nature of the banking and business environment. In a like-mind, Kimaku (2010) expresses further that the uncertainty attached with the dynamic environment is likely to adversely affect employees' competencies, worth, and coping abilities and that organization members do not support change unless compelling reasons convince them to do so. Research according to Acas (2014) has shown that employees are taking their lead on how they feel about their job and how hard they work with their managers who can trigger favourable discretionary behaviour; by demonstrating that they care about how change affects their employees.

The acceptance or rejection of change may be capitalized on the nature of individual employees. Employees are of five categories; the innovators (often trying to change behaviour), early adopters (often trying to initiate change based on the need), early majority (often willing to adopt new ideas and behaviours faster than average), late majority (often sceptical about change consequence and often be the last to adopt change) and the laggards (too tradition and sceptical about change and adopt change only when ample information is available). The understanding of these categories of employees demands that management creates awareness of projected change to allow gradual diffusion of attitude and behaviour. Employees are likely to be motivated if the change is a better one and can yield result. Also, the degree to which the change is consistent with the 'values, experiences and needs' of the adopters, the complexity of the change and its experiment-ability can influence the acceptability or rejection of change by bank employees. 
Most often bank employees must undergo intensive courses and training to be able to adapt to technology, global financial and economy's induced change. On many occasions, fraud alert appears to institute banks' unplanned change. Other factors contributing to unplanned change are new technology, competition, economic condition, industrial policies, regulation, and legal framework of the country. Naveed et al. (2017) also investigated process, attitude, tolerance change, leadership communication, structure, and culture as the main predictors of organizational change. Sequel to the above discussion, this study was related to the North Central Nigeria, selecting some banks.

The main purpose of the study was to analyse the effects of organizational change on employees' performance in banks in North Central Nigeria. The specific purposes of the study were to:

i. Investigate the significant effects of tolerance to change and the activities of fraud on the performance of banks employee in North Central Nigeria.

ii. Investigate the significant effects of change drivers on banks' employee performance in North Central Nigeria.

iii. Investigate the significant relationship that exists between employee motivation, perceived change acceptance and perceived change rejection in banks in North Central Nigeria.

iv. Investigate the prime factors influencing employees' acceptance of organizational change in banks in North Central Nigeria.

\section{LITERATURE REVIEW}

There has been varying attempt by different scholars to provide a holistic view of organizational change. This is sequel to the fact that organizational change itself is equivocal. It may be inclined by the angle from which an individual has directed his/her investigation. The conceptual clarification of organization change may be made considering:

i. Organizational development: Proactive search and identification of development opportunities (Codreanu, 2010).

ii. External environmental force: Organizational change in response to the economic, social, technological and political dynamics of an organization's external environment.

iii. Internal environmental force: Organizational change with respect to employee job design, mission, strategies, policies, organizational structure, operation/process design, organizational culture and product/services.

Several definitions provided by different scholars have captured one or more of the elements discussed. 
The table 1 shows the definitions of organizational change.

TABLE 1. CONCEPTUAL CLARIFICATION OF "ORGANIZATIONAL CHANGE"

\begin{tabular}{|l|l|l|}
\hline S/N & Author & Definition \\
\hline 1 & McNamara (2011) & $\begin{array}{l}\text { Organizational change generally means rightsizing, new } \\
\text { development and change in technologies, rescheduling } \\
\text { operations and major partnerships. }\end{array}$ \\
\hline 2 & Khosa et al. (2015) & $\begin{array}{l}\text { Organizational change involves mission changes, strategic } \\
\text { changes, operational changes (including structural change), } \\
\text { technological changes, changing the attitudes and } \\
\text { behaviours of personnel, counter resistance from different } \\
\text { employees of companies and align them to strategic } \\
\text { directions of the organization. }\end{array}$ \\
\hline 3 & Karanja (2015) & $\begin{array}{l}\text { Organizational change is any action or set of actions } \\
\text { resulting in a shift in direction or process that affects the } \\
\text { way an organization works. }\end{array}$ \\
\hline 4 & Çelik and Ozsoy (2016) & $\begin{array}{l}\text { Organizational change can be defined as change in } \\
\text { organizational structure, its systems, employees and } \\
\text { relation of between them in a planned or non-planned way. }\end{array}$ \\
\hline 5 & Pakdel (2016) & $\begin{array}{l}\text { Change is the defined as the process through which } \\
\text { something becomes different. }\end{array}$ \\
\hline
\end{tabular}

Source: Authors

Organizational Change looks both at the process in which any organization changes its operational methods, technologies, organizational structure, whole structure, or strategies, as well as what effects these changes have on it. Organizational change is usually re-engineered or accepted in quick reaction to or as a result of external pressure (from global or domestic forces outside the banks) or internal pressures (arising process, operational and structure changes). The view of Ezekiel (2007) expressed those two types of forces exist in managing change process generally; such as "the driving forces that set in motion the change process and the restraining forces that resist the change process in organizations". Daniel (2019: 59) added that "this clearly reveals that one of the major problems confronting managers in managing any type of change is resistance to change". Daniel (2019) stated that:

Change Management is a process involving unfreezing, moving, and refreezing values, practices, and procedures within organizations. Unfreezing refers to the creation of a perceived discrepancy between the existing and ideal state of an organization that generates a desire for change and lowers people's resistance to change. 
There is need for managers to adopt the most effective approach to mobilize support for and embracement of change in their organization. Resistance to change is as a result of gap in the managerial approach to change.

The environment of banks in Nigeria constantly calls for change. This understanding made Ojo (2010) to express that the need for a change-oriented approach in their management becomes critical; because many banks failed in the past as a result of the complexity of change. Banks must be reactive to change emanating from uncontrollable forces in the broad environment and as well be proactive enough by initiating change-oriented approach to take advantage of domestic and the global competition. A more proactive viewpoint is that it is triggered by a progressive manager. This is one of the reasons that Systematic Important Banks engage in constant human capital development in Nigeria. The Systematic Important Banks also engage in proactive approach to change by periodically electing Chief Executive Officer to lead the banks with new ideas and intellect. Banks have strategically taken advantage of engineered change for some reasons apart from being proactive. These are however in tandem with the perspectives of Lewin's Change Management theory.

Based on the perspective of teleological theory (also known as planned change), the rationale behind a 'continuous process of goal-setting, execution, evaluation and restructuring' that permeate the Systematic Important Banks is to facilitate the retention of their status as the spinal cord of the Nigerian economy. Teleological theory of change states that the actions of the executives of the Systematic Important Banks are purposive; goal is the final cause for guiding movement of an entity. Lewin's Change Management Model advocates that the essence of managing change (by promoting effective communications and empowering employees) is to initiate best practices to bring about operation effectiveness and efficiency. This implies that a bank that is reactive or proactive to change is conscious of its operations environment. Managing change reflects the technical ground for best practices, and a good fit between the bank staff and banking operations/processes. Failure to take cognizance of this is likely to bring about constant struggle to survive or death in the banking environment. Dialectical theory assumes that a bank is like a multi-cultural society which has opposing values. When one specific force dominates over others, a new value is created, and the establishment of new goal becomes inevitable. In respect of this, organizational change is likely to occur. The Systematic Important Banks are observed to have target for their organizational change.

Yang, Zhuo and Yu (2009) asserted that the most popularly known targets of organizational change include 'vision, strategy, culture, structure, system, operation technology, and leadership style'. Vision indicates what banks want to achieve at the long run (which is expressed in their organizational core value). The core values of these banks are influence by change emanating from the interplay of external 
environmental forces. Realistically, many executives are guilty of not revisiting the core value of their banks when organizational change occurs. On a practical note, the vision of organizations is often reshaped by changes caused by uncontrollable environmental forces. Better way of protecting the vision of the organization is through the development of new strategy or change in the existing strategy.

A strategy is a roadmap deigned for an organization to facilitate or secure its long-term goals. The target of strategic management is the pursuit of corporate goal given adequate resources. Thus, strategy change is deemed very important to cope with organizational change caused by external environment. Strategy change may be in the form of corporate strategy change (cost leadership, differentiation and focus), overall strategy change (broad strategic thinking within the banking industry) and global expansion strategy change.

Culture is another target of organizational change. For instance, individual bankers have their values and norms which they guide and protect. There is high probability of culture clash among bankers, and this is likely to affect their performance and the broad corporate goals. Banks may alter the content of their values and norms to disallow the possible culture clash among their employees. Organizational change resulting from content adjustment of values and norms depends largely on the ability of banks to manage and sustain explicit culture.

Structure change is also considered paramount to change the operation outlook of banks. For instance, First Bank recently established a cleavage between retail business unit and retail service unit; each reporting to different heads but under the CEO of the bank. The staff members in the retail service unit report to Head Branch Service (HBS); the HBS reports to the Cluster Operation and Service Manager (COSM); the COSM reports to the Group Head of Operation and Services (GH); the GH reports to the Group Executive Technology and Service (GE) who reports to the General Managing Director. The staff members in the retail business unit report to the Business Manager (BM); the BM reports to the Business Development Manager (BDM); the BDM reports to the Group Head (GH); the $\mathrm{GH}$ reports to the Group Executive (GE); and the GE reports to the Deputy Managing Director (DMD). The structure change is in line with the EPIC model (Entrepreneurship, Professionalism, Innovativeness and Centrism). Bond (2008) presupposed that the idea behind the coordination of a structure is to establish effective change in order to sustain a turnaround within the organization.

The goals of organizational change are multi-faceted, but the major one is to improve the organization mergence, crisis intervention and to overcome day to day hauling competition (Isern and Pung, 2007). It is observed that the idea of structure change is to enhance an efficient system that can create competitive edge in the banking environment. Based on this perspective, Daniel (2019) viewed the "management of change as the systemic approach and application of knowledge, tools and resources to deal with change". Ememe (2017) expressed that these organizational change variables 
intercommunicate. Strategy change, structure change, system change, and leadership change are all driven at achieving the vision of an organization.

The process of organization change, the "systematic viewpoint" has to be taken, so that different change targets can be considered as a whole to achieve the organizational change successfully. Khosa et al. (2015) added that "organizational change includes Mission changes, Strategy changes, operational changes (including structural change), technological changes, changing the attitudes and behaviours of personnel, counter resistance from different employees of companies and align them to strategic directions of the organization". Collins and Porras (2002) cited in Dalati (2017) expressed that the challenges facing leading and visionary organizations is tied to the sustainability of effective change in such a way that mission and core values will be preserved and enhance the management of changing cultural and operating practices and specific goals and strategies of the organizations. Figure 2.1 shows that tolerance to change and the activities of fraudsters can predict bank employees' performance. The study of Khosa et al. (2015) proved that tolerance to change has effect on employees' performance in the banking sector. Also, Mawutor, Enofe, Embele, Ndu \& Awodola (2019) revealed that fraudulent activities have insignificant effect on performance. In addition, strategy change, organizational structuring, attitude of employees towards change and organizational culture all has possible effects on employees' performance in banks.

\section{RESEARCH METHODOLOGY}

The study is descriptive in nature; thus, two strategies were adopted. These are strategy and survey strategy. The search strategy involves review of scientific studies while the survey strategy focused on the use of questionnaire for data collection. This study is more of survey with little element of systematic review. The choice of the strategies was sequel to the context in which the study was conducted, the objectives of the study and the drive towards gathering quality data. This research identified three-inone aggregation groups of interest; these are First Bank of Nigeria, United Bank for Africa and Zenith Banks in the North central Nigeria. These banks are referred to as 'three-in-one' because they are Systematic Important Banks (SIBs). The SIBs are the pillars of Nigerian economy; thus, the Central Bank of Nigeria makes no financial or economic policy without reference to them. Meanwhile, two states (Kogi State and Benue State) were the study's quantitative attributes (areas of interest). Based on the focus of this study, the sub-population of SIBs in the North Central (for Benue State) is 168 potential respondents and the sub-population of SIBs in the North Central (for Kogi State) is 202 potential respondents. 
Aduku, D., J., Hassan, O.,M., \& Nafiu, A., T.

DESCRIPTIVE ANALYSIS OF PERCEIVED CHANGE ACCEPTANCE AND CHANGE REJECTION IN BANKS IN NORTH CENTRAL NIGERIA

For the sample size, given the population for each state (Benue- 168 and Kogi- 202) in the North Central, the research adopted Sallant and Dillman's (1994) method. The formula is stated below:

$$
N_{s}=\frac{N_{p}(p)(1-p)}{\left(N_{p}-1\right)\left(\frac{B}{C}\right)^{2}+(p)(1-p)}
$$

Where:

$\mathrm{Ns}=$ completed sample size required

$\mathrm{Np}=$ Sample population

$\mathrm{P}=$ proportion expected to answer in a certain way ( $50 \%$ or 0.5 is most conservative)

$B=$ acceptable level of sampling error $(0.05=+5 \% ; 0.03=+3 \%)$

$C=Z$ statistic associated with the confidence interval $(1.64 \overline{5}=90 \%$ confidence level;

$1.960=95 \%$ confidence level; $2.576=99 \%$ confidence level)

The total sample size of the study was 189. The sub-samples for the focused states were based on the Bowley's Proportional Allocation. This is because the SIBs in Kogi State make the majority, and virtually the sub-sample method allocates $54.5 \%$ to SIBs in Kogi State in terms of computation.

The sub-samples are shown below.

Kogi State $=202(189) / 370=103.1837838=103$

Benue State $=168(189) / 370=85.81621622=86$

For this study, multistage random sampling technique was adopted. The data that were generated for the study were analysed using descriptive analytical techniques.

\section{DATA PRESENTATION AND ANALYSIS}

TABLE 2. DESCRIPTIVE STATISTICS OF EMPLOYEES' CHANGE REJECTION FACTORS

\begin{tabular}{|l|c|c|c|c|}
\hline \multirow{2}{*}{ Responses } & \multicolumn{2}{|c|}{ Benue State } & \multicolumn{2}{c|}{ Kogi State } \\
\cline { 2 - 5 } & Mean & $\begin{array}{c}\text { Std. } \\
\text { Dev. }\end{array}$ & Mean & Std. Dev. \\
\hline Change types & 1.3659 & .48463 & 1.4583 & .50088 \\
\hline Change enabler & 1.3171 & .46820 & 1.3438 & .47745 \\
\hline Change methods & 1.4390 & .49932 & 1.4271 & .49725 \\
\hline Perceived change outcomes & 1.4634 & .50173 & 1.2708 & .44672 \\
\hline Change driving force & 1.3659 & .48463 & 1.4479 & .49989 \\
\hline
\end{tabular}

Source: Field Survey (2020)

Table 2 shows the descriptive statistics of employees' change rejection factors in Benue State. Factors such as change types, change enabler, change methods, perceived change outcomes and change driving force were identified. The results show change types (mean= 1.3659; standard deviation= 0.48463 ), change enabler (mean $=1.3171$; standard deviation $=0.46820)$, change methods $($ mean $=$ 
Aduku, D., J., Hassan, O.,M., \& Nafiu, A., T.

DESCRIPTIVE ANALYSIS OF PERCEIVED CHANGE ACCEPTANCE AND CHANGE REJECTION IN BANKS IN NORTH CENTRAL NIGERIA

1.4390; standard deviation $=0.49932$ ), perceived change outcomes (mean $=1.4634$; standard deviation= 0.50173 ), and change driving force (mean $=1.3659$; standard deviation= 0.48463 ). The results show that perceived change outcomes have the highest means core with the highest divergence. Based on mean score ranking, the employees' change rejection factors such as perceived change outcomes and change methods are the strongest factors. Change types and change driving force have the same mean scores, and are stronger, while change enabler makes the least factor. By implication, perceived change outcomes and change methods are strongest factors influencing employees' rejection of organizational change in Benue State.

Table 2 also indicates the descriptive statistics of employees' change rejection factors in Kogi State. Change types (mean $=1.4583$; standard deviation $=0.50088)$, change enabler (mean=1.3438; standard deviation $=0.47745$ ), change methods (mean $=1.4271$; standard deviation $=0.49725$ ), perceived change outcomes (mean=1.2708; standard deviation= 0.44672), and change driving force (mean=1.4479; standard deviation $=0.49989$ ) are factors influencing employees' rejection of organizational change. Ranking the mean scores, the three strongest employees' change rejection factors are change types, change driving force and change methods. Bank employees are likely to reject organizational change on the basis of change type or methods. The forces behind change implementation are also likely to cause employees' change rejection, particularly when they are perceived inverse. Change enabler appears to be stronger employees' change rejection factor, while perceived change outcomes makes the least factor influencing employees' change rejection. The results however show that change types are the strongest factor influencing employees' rejection of organizational change in banks in Kogi State.

TABLE 3. DESCRIPTIVE STATISTICS ON EXTENT OF PRIORITIES AND STRATEGIC FOCUS

\begin{tabular}{|l|l|l|l|l|}
\hline \multirow{2}{*}{\multicolumn{1}{|c|}{ Responses }} & \multicolumn{2}{c|}{ Benue State } & \multicolumn{2}{c|}{ Kogi State } \\
\cline { 2 - 5 } & \multicolumn{1}{c|}{ Mean } & Std. Dev. & \multicolumn{1}{c|}{ Mean } & Std. Dev. \\
\hline Account acquisition & 2.5000 & 1.30762 & 2.4375 & 1.22957 \\
\hline Relational management & 2.0366 & .72767 & 2.6875 & 1.08882 \\
\hline Deposit growth & 1.9634 & 1.18055 & 2.1771 & 1.24811 \\
\hline Service improvement & 2.1829 & 1.27781 & 2.5938 & 1.34225 \\
\hline Cost optimization & 2.1220 & 1.01093 & 2.4688 & 1.32151 \\
\hline Agent banking & 2.5732 & 1.37014 & 2.4792 & 1.44353 \\
\hline Non-interest income & 2.7439 & 1.17390 & 3.1771 & 1.17871 \\
\hline Creation of quality assets & 2.2927 & 1.27161 & 2.2500 & 1.34556 \\
\hline
\end{tabular}

Source: Field Survey (2020)

Table 3 shows the descriptive statistics of the extent of priorities and strategic focus of bank in Benue State. The table indicates that the priorities and strategic focuses of bank in Benue State are account 
acquisition ( mean=2.5000; standard deviation $=1.30762$ ), relational management (mean=2.0366; standard deviation $=0.72767)$, deposit growth $($ mean=1.9634; standard deviation $=1.18055)$, service improvement $($ mean=2.1829; standard deviation $=1.27781)$, cost optimization $($ mean=2.1220; standard deviation $=1.01093)$, agent banking $($ mean $=2.5732$; standard deviation $=1.37014)$, non-interest income $($ mean=2.7439; standard deviation $=1.17390)$, and creation of quality assets $($ mean=2.2927; standard deviation $=1.27161$ ). The mean ranking shows that non-interest income (first), agent banking (second), account acquisition (third), creation of quality assets (fourth), relational management (fifth), service improvement (sixth), cost optimization (seventh) and deposit growth (eighth). Interestingly, noninterest income has the highest mean score with almost the least divergence. This implies that the data spread around the mean.

Table 3 shows the descriptive statistics of the extent of priorities and strategic focus of bank in Kogi State. Table 3 indicates that the priorities and strategic focuses of bank in Kogi State are account acquisition ( mean=2.4375; standard deviation $=1.22957)$, relational management $($ mean=2.6875; standard deviation $=1.08882)$, deposit growth $($ mean=2.1771; standard deviation $=1.24811)$, service improvement $($ mean=2.5938; standard deviation $=1.34225)$, cost optimization $($ mean=2.4688; standard deviation $=1.32151)$, agent banking $($ mean $=2.4792$; standard deviation $=1.44353)$, non-interest income (mean=3.1771; standard deviation $=1.17871)$, and creation of quality assets (mean=2.2500; standard deviation $=1.34556)$. The mean ranking shows that non-interest income (first), relational management (second), service improvement (third), agent banking (fourth), cost optimization (fifth), account acquisition (sixth), creation of quality assets (seventh) and deposit growth (eighth). Non-interest income also has the highest mean score with almost the least divergence in Kogi State.

TABLE 4. DESCRIPTIVE STATISTIC OF CHANGE STIMULATOR IN THE BANK'S INTERNAL ENVIRONMENT

\begin{tabular}{|l|l|l|l|l|}
\hline \multirow{2}{*}{ Responses } & \multicolumn{2}{c|}{ Benue State } & \multicolumn{2}{c|}{ Kogi State } \\
\cline { 2 - 5 } & \multicolumn{1}{|c|}{ Mean } & Std. Dev. & Mean & Std. Dev. \\
\hline Structure & 2.5000 & 1.24969 & 2.6771 & 1.34942 \\
\hline Bank's culture & 2.1829 & 1.29699 & 2.3854 & 1.50347 \\
\hline Mode of operation & 2.5122 & 1.20947 & 2.5833 & 1.33509 \\
\hline Customer-centrism & 1.9878 & 1.17056 & 2.2604 & 1.43816 \\
\hline Need for professionalism & 2.1098 & 1.39670 & 2.5312 & 1.22219 \\
\hline
\end{tabular}

Source: Field Survey (2020)

Table 4 shows the descriptive statistic of five change stimulator in the bank's internal environment in Benue State. The table shows that structure (mean=2.5000; standard deviation $=1.24969$ ), bank's culture $($ mean=2.1829; standard deviation $=1.29699)$, mode of operation (mean=2.5122; standard deviation $=1.20947)$, customer-centrism $($ mean=1.9878; standard deviation $=1.17056)$ and need for 
Aduku, D., J., Hassan, O.,M., \& Nafiu, A., T.

DESCRIPTIVE ANALYSIS OF PERCEIVED CHANGE ACCEPTANCE AND CHANGE REJECTION IN BANKS IN NORTH CENTRAL NIGERIA

professionalism (mean=2.1098; standard deviation $=1.39670$ ) are change stimulator in the bank's internal environment. Among the stimulators, banks' mode of operation has the strongest mean score. It is observed that mode of operation appears to be the strongest change stimulator in the bank's internal environment in Benue State.

Table 4 shows the descriptive statistic of five change stimulator in the bank's internal environment in Kogi State. The table indicates that structure (mean=2.6771; standard deviation $=1.34942)$, bank's culture (mean=2.3854; standard deviation $=1.50347$ ), mode of operation (mean=2.5833; standard deviation $=1.33509)$, customer-centrism $($ mean=2.2604; standard deviation $=1.43816)$ and need for professionalism (mean=2.5312; standard deviation $=1.22219$ ) are change stimulator in the bank's internal environment. The study shows that structure is the strongest change stimulator in the bank's internal environment.

TABLE 5. DESCRIPTIVE STATISTICS OF FACTORS INFLUENCING ACCEPTANCE OF ORGANIZATIONAL CHANGE

\begin{tabular}{|l|l|l|l|l|}
\hline \multicolumn{2}{|c|}{ Responses } & \multicolumn{2}{|c|}{ Benue State } & \multicolumn{2}{c|}{ Kogi State } \\
\cline { 2 - 5 } & \multicolumn{1}{|c|}{ Mean } & Std. Dev. & Mean & Std. Dev. \\
\hline $\begin{array}{l}\text { Acceptance of change as a result of } \\
\text { perceived advantage }\end{array}$ & 2.2073 & 1.24462 & 1.8542 & 1.02576 \\
\hline $\begin{array}{l}\text { Acceptance of change subject to } \\
\text { compatibility }\end{array}$ & 2.1707 & 1.15261 & 2.2708 & 1.16510 \\
\hline $\begin{array}{l}\text { Acceptance of change based on } \\
\text { complexity }\end{array}$ & 2.3537 & 1.11524 & 2.8021 & 1.09179 \\
\hline Acceptance of change to give things trial & 2.1220 & 1.17998 & 2.2500 & 1.30586 \\
\hline The attitude of employees towards change & 2.4878 & 1.35395 & 2.5104 & 1.28140 \\
\hline Employee commitment toward change & 2.2073 & 1.33090 & 2.1771 & 1.28959 \\
\hline Tolerance to change & 2.1707 & 1.32222 & 2.1354 & 1.16637 \\
\hline Employee motivation & 2.4390 & 1.28714 & 2.5625 & 1.32833 \\
\hline
\end{tabular}

Source: Field Survey (2020)

Table 5 shows the descriptive statistics of factors influencing acceptance of organizational change in banks in Benue State. Perceived advantage (mean= 2.2073; standard deviation=1.24462), acceptance of change subject to compatibility (mean=2.1707; standard deviation=1.15261), acceptance of change based on complexity (mean= 2.3537; standard deviation=1.11524), acceptance of change to give things trial (mean= 2.1220; standard deviation= 1.17998), the attitude of employees towards change (mean= 2.4878; standard deviation= 1.35395), employee commitment toward change (mean=2.2073; standard deviation $=1.33090)$, tolerance to change (mean= 2.1707; standard deviation= 1.32222$)$, and employee motivation (mean= 2.4390; standard deviation= 1.28714) are factors influencing acceptance of organizational change in Benue State. The study shows that the attitude of employees towards 
Aduku, D., J., Hassan, O.,M., \& Nafiu, A., T.

DESCRIPTIVE ANALYSIS OF PERCEIVED CHANGE ACCEPTANCE AND CHANGE REJECTION IN BANKS IN NORTH

CENTRAL NIGERIA

change appears to be the strongest factors influencing acceptance of organizational change in Benue State.

Table 5 also shows the descriptive statistics of factors influencing acceptance of organizational change in banks in Kogi State. Perceived advantage (mean= 1.8542; standard deviation=1.02576), acceptance of change subject to compatibility (mean=2.2708; standard deviation=1.16510), acceptance of change based on complexity (mean= 2.8021; standard deviation=1.09179), acceptance of change to give things trial (mean=2.2500; standard deviation= 1.30586), the attitude of employees towards change (mean= 2.5104; standard deviation=1.28140), employee commitment toward change (mean=2.1771; standard deviation=1.28959), tolerance to change (mean=2.1354; standard deviation=1.16637), and employee motivation (mean= 2.5625; standard deviation= 1.32833) are factors influencing acceptance of organizational change in banks in Benue State. The result shows that acceptance of change based on complexity is the strongest factors influencing acceptance of organizational change in banks in Kogi State.

TABLE 6A. KMO AND BARTLETT'S TEST OF FACTORS INFLUENCING ACCEPTANCE OF ORGANIZATIONAL CHANGE IN BENUE STATE

\begin{tabular}{|l|l|l|}
\hline \multicolumn{2}{|l|}{ Kaiser-Meyer-Olkin Measure of Sampling Adequacy. } & .832 \\
\hline \multirow{3}{*}{ Bartlett's Test of Sphericity } & Approx. Chi-Square & 945.767 \\
\cline { 2 - 3 } & Df & 28 \\
\cline { 2 - 3 } & Sig. & .000 \\
\hline
\end{tabular}

Source: Field Survey (2020)

The Table 6a above shows the KMO and Bartlett's Test of factors influencing acceptance of organizational change in Benue State. The table shows that the Bartlett's Test of Sphericity $(p<0.01)$ and the Kaiser-Meyer-Olkin (KMO) measures of sampling adequacy index (with the value of 0.832 ) confirms that the data fit in for the principal component Analysis (PCA). The KMO value of 0.832 is closer to 1 , and it is believed to be a good one. Therefore, the KMO end result is considered important and sufficient enough. The simple implication of Bartlett's Test of Sphericity $(p<0.01)$ is that the correlation matrix significantly varies from identity matrix (in which the correlation among variables is equal to zero).

TABLE 6B. COMMUNALITIES ANALYSIS OF FACTORS INFLUENCING ACCEPTANCE OF ORGANIZATIONAL CHANGE IN BENUE STATE

\begin{tabular}{|l|c|c|}
\hline Factors & Initial & Extraction \\
\hline $\begin{array}{l}\text { Acceptance of change as a result of perceived } \\
\text { advantage }\end{array}$ & 1.000 & .915 \\
\hline
\end{tabular}


Aduku, D., J., Hassan, O.,M., \& Nafiu, A., T.

DESCRIPTIVE ANALYSIS OF PERCEIVED CHANGE ACCEPTANCE AND CHANGE REJECTION IN BANKS IN NORTH CENTRAL NIGERIA

\begin{tabular}{|l|l|l|}
\hline Acceptance of change subject to compatibility & 1.000 & .718 \\
\hline Acceptance of change based on complexity & 1.000 & .922 \\
\hline Acceptance of change to give things trial & 1.000 & .931 \\
\hline The attitude of employees towards change & 1.000 & .885 \\
\hline Employee commitment toward change & 1.000 & .720 \\
\hline Tolerance to change & 1.000 & .942 \\
\hline Employee motivation & 1.000 & .858 \\
\hline
\end{tabular}

Extraction Method: Principal Component Analysis

Table $6 \mathrm{~b}$ indicates that the communalities analysis of variables (in which each of the variable has the value above $4 \%$ ). Communalities show the relationship between the variable and all other variables. For principal component extraction, the initial communalities value is always equal to 1.0 for correlation analyses. Extraction communalities are estimate of the variance in each variable accounted for by the components. The table shows that communalities for acceptance of change as a result of perceived advantage (0.915), acceptance of change subject to compatibility (0.718), acceptance of change based on complexity (0.922), acceptance of change to give things trial (0.931), the attitude of employees towards change (0.885), employee commitment toward change $(0.720)$, tolerance to change $(0.942)$ and employee motivation (0.858) are all important. In view of this, since the value are higher than 0.4 $(4 \%)$, it is an evidence that the extracted components represent the variables well.

TABLE 6C. TOTAL VARIANCE OF FACTORS INFLUENCING ACCEPTANCE OF ORGANIZATIONAL CHANGE IN BENUE STATE

\begin{tabular}{|l|l|l|l|l|l|l|}
\hline \multirow{2}{*}{$\begin{array}{l}\text { Compon } \\
\text { ent }\end{array}$} & \multicolumn{5}{|l|}{ Initial Eigenvalues } & \multicolumn{2}{l|}{ Extraction Sums of Squared Loadings } \\
\cline { 2 - 7 } & Total & $\begin{array}{l}\% \text { of } \\
\text { Variance }\end{array}$ & $\begin{array}{l}\text { Cumulative } \\
\%\end{array}$ & Total & $\begin{array}{l}\text { \% of } \\
\text { Variance }\end{array}$ & $\begin{array}{l}\text { Cumulative } \\
\%\end{array}$ \\
\hline 1 & 5.496 & 68.696 & 68.696 & 5.496 & 68.696 & 68.696 \\
\hline 2 & 1.396 & 17.447 & 86.143 & 1.396 & 17.447 & 86.143 \\
\hline 3 & .675 & 8.443 & 94.586 & & & \\
\hline 4 & .205 & 2.560 & 97.146 & & & \\
\hline 5 & .120 & 1.501 & 98.647 & & & \\
\hline 6 & .052 & .650 & 99.296 & & & \\
\hline 7 & .034 & .426 & 99.722 & & & \\
\hline 8 & .022 & .278 & 100.000 & & & \\
\hline
\end{tabular}

Table 6c, the 'Total' column illustrates the amount of variance in the original variables accounted for by each component. The $\%$ of variance column gives the exact ratio, which is expressed as a percentage of the variance accounted for by each of the component to the total variance in all of the variables. The cumulative $\%$ column gives the percentage of variance accounted for by the first $n$ components. The 
Aduku, D., J., Hassan, O.,M., \& Nafiu, A., T.

DESCRIPTIVE ANALYSIS OF PERCEIVED CHANGE ACCEPTANCE AND CHANGE REJECTION IN BANKS IN NORTH

CENTRAL NIGERIA

table above indicates that the first and second factors have the Eigenvalue value of 5.496 and 1.396 . The value is equal or greater than 1 , and this shows more variance. The percent of the explained variance are 68.696 and 17.447. Other factors ranging from 3 to 8 have Eigenvalue value less than 1. Therefore, they are explained as lesser variance.

TABLE 7A. KMO AND BARTLETT'S TEST OF FACTORS INFLUENCING ACCEPTANCE OF ORGANIZATIONAL CHANGE IN KOGI STATE

\begin{tabular}{|l|l|l|}
\hline Kaiser-Meyer-Olkin Measure of Sampling Adequacy. & .845 \\
\hline Bartlett's Test of Sphericity & Approx. Chi-Square & 854.206 \\
\cline { 2 - 3 } & Df & 28 \\
\cline { 2 - 3 } & Sig. & .000 \\
\hline
\end{tabular}

Source: Field Survey, 2020

Table 7a show the KMO and Bartlett's Test of factors influencing acceptance of organizational change in Kogi State The table above shows that the Bartlett's Test of Sphericity $(p<0.01)$ and the KaiserMeyer-Olkin (KMO) measures of sampling adequacy index (with the value of 0.845 ) confirms that the data fit in for the principal component Analysis (PCA). The KMO value of 0.845 is closer to 1 , and it is believed to be a good one. Therefore, the KMO end result is considered important and sufficient enough. The simple implication of Bartlett's Test of Sphericity $(p<0.01)$ is that the correlation matrix significantly varies from identity matrix (in which the correlation among variables is equal to zero).

TABLE 7B: COMMUNALITIES ANALYSIS OF FACTORS INFLUENCING ACCEPTANCE OF ORGANIZATIONAL CHANGE IN KOGI STATE

\begin{tabular}{|l|c|c|}
\hline Factors & Initial & Extraction \\
\hline $\begin{array}{l}\text { Acceptance of change as a result of perceived } \\
\text { advantage }\end{array}$ & 1.000 & .876 \\
\hline Acceptance of change subject to compatibility & 1.000 & .454 \\
\hline Acceptance of change based on complexity & 1.000 & .913 \\
\hline Acceptance of change to give things trial & 1.000 & .891 \\
\hline The attitude of employees towards change & 1.000 & .884 \\
\hline Employee commitment toward change & 1.000 & .833 \\
\hline Tolerance to change & 1.000 & .828 \\
\hline Employee motivation & 1.000 & .888 \\
\hline
\end{tabular}

Extraction Method: Principal Component Analysis

Table $7 \mathrm{~b}$ indicates that the communalities analysis of variables (in which each of the variable has the value above $4 \%$ ). Communalities show the relationship between the variable and all other variables. For principal component extraction, the initial communalities value is always equal to 1.0 for correlation analyses. Extraction communalities are estimate of the variance in each variable accounted for by the components. The table shows that communalities for acceptance of change as a result of perceived 
Aduku, D., J., Hassan, O.,M., \& Nafiu, A., T.

DESCRIPTIVE ANALYSIS OF PERCEIVED CHANGE ACCEPTANCE AND CHANGE REJECTION IN BANKS IN NORTH CENTRAL NIGERIA

advantage (0.876), acceptance of change subject to compatibility (0.454), acceptance of change based on complexity (0.913), acceptance of change to give things trial $(0.891)$, the attitude of employees towards change $(0.884)$, employee commitment toward change $(0.833)$, tolerance to change $(0.828)$ and employee motivation (0.888) are all important. In view of this, since the value are higher than 0.4 $(4 \%)$, it is an evidence that the extracted components represent the variables well.

TABLE 7C. TOTAL VARIANCE OF FACTORS INFLUENCING ACCEPTANCE OF ORGANIZATIONAL CHANGE IN KOGI STATE

\begin{tabular}{|l|l|l|l|l|l|l|}
\hline \multirow{2}{*}{$\begin{array}{l}\text { Compone } \\
\text { nt }\end{array}$} & \multicolumn{4}{|l|}{ Initial Eigenvalues } & \multicolumn{3}{l|}{ Extraction Sums of Squared Loadings } \\
\cline { 2 - 7 } & Total & $\begin{array}{l}\% \text { of } \\
\text { Variance }\end{array}$ & $\begin{array}{l}\text { Cumulative } \\
\%\end{array}$ & Total & $\begin{array}{l}\text { \% } \\
\text { Variance }\end{array}$ & $\begin{array}{l}\text { Cumulative } \\
\%\end{array}$ \\
\hline 1 & 5.559 & 69.493 & 69.493 & 5.559 & 69.493 & 69.493 \\
\hline 2 & 1.007 & 12.585 & 82.078 & 1.007 & 12.585 & 82.078 \\
\hline 3 & .762 & 9.526 & 91.603 & & & \\
\hline 4 & .241 & 3.010 & 94.614 & & & \\
\hline 5 & .150 & 1.875 & 96.489 & & & \\
\hline 6 & .133 & 1.664 & 98.153 & & & \\
\hline 7 & .108 & 1.348 & 99.502 & & & \\
\hline 8 & .040 & .498 & 100.000 & & & \\
\hline
\end{tabular}

Table 7c shows the 'Total' column illustrates the amount of variance in the original variables accounted for by each component. The $\%$ of variance column gives the exact ratio, which is expressed as a percentage of the variance accounted for by each of the component to the total variance in all of the variables. The cumulative \% column gives the percentage of variance accounted for by the first $n$ components. The table above indicates that the first and second factors have the Eigenvalue value of 5.559 and 1.007. The value is equal or greater than 1 , and this shows more variance. The percent of the explained variance are 69.493 and 12.585 . Other factors ranging from 3 to 8 have Eigenvalue value less than 1 . Therefore, they are explained as lesser variance.

\section{CONCLUSION AND RECOMMENDATIONS}

One major way that banks have become relevant in the industry is organizational change. The SIBS have been able to adapt to their environment and become the most important banks because of consistent organizational change implementation. The banks have been able to choose change model which (they believe) have great implication for their structure, culture, vision, strategies, and employees' performance. Banks leaders are conversant with the fact that organizational change is pivoted to 
banking practices. They are also aware that leading organizational change is very challenging. This is because employees that will help in achieving the outcomes of the change may exhibit rejection attitude. Employees' change resistance or rejection is subject to numerous factors. This study has proven that factors such as change types, change enabler, change methods, perceived change outcomes and change driving force are subject to employees' change resistance. Though, there are other factors that can explain why employees resist change, but the aforementioned factors play key roles in employees' change rejection. There are paramount reasons why change rejection may be costly for organizations. Employees change rejection may be instrumental to failure in banking businesses (in terms of their products and services). The study recommended that bank leaders should monitor change outcomes and change methods in Benue State, and that change type or methods should be given strong attention in Kogi State. The study recommended also that positive attitude of employees towards change should be motivated to increase acceptance of organizational change in Benue State.

\section{REFERENCES}

Acas (2014). How to manage change. Retrieved on 25/06/2019 from http://m.acas.org.uk/media/pdf/q/q/Acas-How-to-manage-change-advisory-booklet.pdf

Bond, C. (2008). Outcome Realization and Organizational Change Management-the Tasmania Government Approach, Department of Premier and Cabinet, Tasmania.

Çelik, A. and Ozsoy, N. (2016). Organizational Change: Where Have We Come From and Where Are We Going? International Journal of Academic Research in Accounting, Finance and Management Sciences. 6(1): 134-141. DOI: 10.6007/IJARAFMS/v6-i1/2004

Codreanu, A. (2010). Organizational Change: A Matter of Individual and Group Behavior Transformation. Journal of Defense Resources Management. 1(1): 49-56

Collins, J.C. and Porras, J.I. (2002). Built to Last, Adhesives Age. In S. Dalati (eds). Managing Change in Banking Organizations: The Case of a UK Commercial Bank. Journal of Logistics, Informatics and Service Science. 4(1): 34-56

Cummings, T.G. and Worley, C.G. (2009). Organisation Development and Change, Katalog BPS. doi: 10.1007/s13398-014-0173-7.2.

Dalati, S. (2017). Managing Change in Banking Organizations: The Case of a UK Commercial Bank. Journal of Logistics, Informatics and Service Science. 4(1): 34-56

Daniel, C.O. (2019). Effects of Change Management on the Performance of Firms in Nigeria. International Journal of Advances in Scientific Research and Engineering. 5(1): 59-64. DOI: 10.31695/IJASRE.2019.33065

Ememe, J. (2017). Leadership Strategies for Managing Change in the Nigerian Banking Industry. PhD Dissertations: Walden University.

Ezekiel, O. (2007). Change Management in Process Change, Information Systems Control Journal, 20(3): 1-10.

Isern, J. and Pung, A. (2007). Harnessing energy to drive organizational change. In: Z.A. Khosa, Z.U. Rehman, A. Asad, M.A. Bilal and N. Hussain (eds). The Impact of Organizational Change on the 
Employee's Performance in the Banking Sector of Pakistan. IOSR Journal of Business and Management. 17(3): 54-61. DOI: 10.9790/487X-17325461

Karanja, A.W. (2015). Organizational Change and Employee Performance: A Case on the Postal Corporation of Kenya. European Journal of Business and Management. 7(11): 232-241

Khosa, Z.A., Rehman, Z.U., Asad, A., Bilal, M.A. and Hussain, N. (2015). The Impact of Organizational Change on the Employee's Performance in the Banking Sector of Pakistan. IOSR Journal of Business and Management. 17(3): 54-61. DOI: 10.9790/487X-17325461

Kimaku, P.M. (2010). Change Management Practices Adopted By Barclays Bank Of Kenya Limited. PhD Dissertation: University Of Nairobi.

Liebhart, M. and Lorenzo, L.G. (2010). Between planned and emergent change: decision maker's perceptions of managing change in organisations. International journal of knowledge, culture and change management, 10(5): 214-225. Retrieved on 22/06/2019 from http:/leprints.Ise.ac.uk/29866/

Mawutor, J.K. , Enofe, A., Embele, K., Ndu, A.R. \& Awodola, O.E. (2019). Fraud and Performance of Deposit Money Banks. Accounting and Finance Research. 8(2), 202-213. doi:10.5430/afr.v8n2p202

McNamara, C. (2011, April 20). Organizational change and development (Managing change). In: Z.A. Khosa, Z.U. Rehman, A. Asad, M.A. Bilal and N. Hussain (eds). The Impact of Organizational Change on the Employee's Performance in the Banking Sector of Pakistan. IOSR Journal of Business and Management. 17(3): 54-61. DOI: 10.9790/487X-17325461

Naveed, R.T., Jantan, A.H., Saidu, M.B. and Bhatti, S.M. (2017). The validation of the organizational change construct using confirmatory factor analysis. Cogent Business \& Management. 4(2017): 110. Retrieved on 23/06/2019 from https://doi.org/10.1080/23311975.2017.1338330

Ojo, A.T., (2010). The Nigerian maladapted financial system: Reforming tasks and development dilemma. Yaba Lagos Nigeria: The CIBN Press Limited.

Pakdel, A. (2016). An Investigation of the Difference in the Impact of Demographic Variables on Employees' Resistance to Organizational Change in Government Organizations of Khorasan Razavi. Procedia - Social and Behavioral Sciences. 230(1), 439 - 446. doi: 10.1016/j.sbspro.2016.09.055

Salant, P., Dillman, I., \& Don, A. (1994). How to conduct your own survey (No. 300.723 S3.).

Westenholz, A. (2013). Main Aspects Regarding the Implication of Change Management in an Organisation, Research in the Sociology of Organizations, 27(1): 1-15.

Yang, R.S., Zhuo, X.Z. and Yu, H.Y. (2009). Organization theory and management: cases, measurements, and industrial applications. Taipei: Yeh-Yeh 